\title{
Dos princípios aos resultados
}

\section{JACQUES MARCOVTTCH}

A

reunião mundial do Rio de Janeiro alcançou o consenso através da lógica do possível. Um consenso sólido com relaçáo aos necessáros para intertomper a degradaçao do planeta e a dualiade necessários para interromper a degradação do planeta e a dualidade sócio-econômica crescente. Dualidade que aumenta as tensóes e os cancros sociais. Uma degradação que ameaça as condiçóes de vida das geraçóes vindouras.

A diplomacia verde conseguiu ampliar a aliança dos que buscam o repensar do desenvolvimento. São autoridades governamentais, cientistas, sindicalistas, lideranças religiosas, empresários que assumiram um compromisso de apoiar uma nova ética planetária. Um compromisso a ser estendido a um número ainda maior de atores sociais.

Distantes da Conferência, estavam os dirigentes dos bancos privados, por exemplo. Profundos conhecedores do "sistema nervoso" da economia de mercado, permaneceram distantes e omissos. Sua ausência foi notada no âmbito do "Business Council for Sustainable Development". Eles representam uma mentalidade baseada no rigor financeiro, respondendo a interesses em busca do maior retorno possível dos investimentos. Uma mentalidade que impóe um curto ciclo de tempo às decisões. Um ciclo incompatível com a dimensão do desafio e da mudança de rumos exigidos por uma nova ética planetária.

\section{A nova ordem (ou desordem) mundial}

Neste final de século, a melhor distribuição dos recursos materiais está longe de ser alcançada. Vive-se um mundo dividido entre os países e no interior próprio dos países. A população mais afluente representa 1/5 da população humana. Na maior parte dos países, a miséria está presente na periferia das grandes cidades e no campo. $O$ país mais rico do mundo tem se mostrado incapaz de integrar os bolsóes de miséria e de reduzir a violência que permeia seu território. 
Nos países menos desenvolvidos as minorias melhor educadas náo têm tido a capacidade de reduzir o fosso entre a sociedade moderna e a maioria de marginalizados. Um fosso que tem induzido os fluxos migratórios indesejados para países mais desenvolvidos. Um abismo que tem sido uma das origens da corrupçáo, da violência, do comércio de recém-nascidos, do narcotráfico e de outros cancros como o ressurgimento de endemias já extirpadas no passado.

No campo político, a democracia é questionada. Eleitos e eleitores revelam uma frustraçáo aguda de expectativas. A diminuiçáo de interesse nas eleiçóes, as críticas permanentes à classe política e um individualismo crescente nos países ocidentais, têm provocado uma busca permanente de novas formas de organizaçáo social e de sistemas de governo. As eleiçóes realizadas recentemente na Europa, especialmente na Alemanha e na França, revelam preocupantes tendências autoritárias em crescimento. Na América Latina, os eventos ocorridos na Venezuela e no Peru alertam para a fragilidade do sistema democrático, que deve ser continuamente consolidado para garantir sua sobrevivência.

Diferentemente da China, nos países do Leste Europeu, a miragem do capitalismo soterrou o sistema decisório centralizado. $O$ aniquilamento dos partidos comunistas privou esses países de sua espinha dorsal, tornando-os amorfos e incapazes de viabilizar seu salto para uma modernizaçáo ansiosamente desejada. O surgimento de novas lideranças, apoiadas por novas estruturas sociais, constitui uma precondiçăo para tornar o projeto da modernizaçáo uma realidade. Na entáo Uniáo Soviética a vinculação de $40 \%$ da capacidade produtiva ao "establishment", militar, cria uma urgente, mas difícil, tarefa de reconversáo industrial.

A liberalizaçáo do comércio internacional é defendida nos discursos proferidos nos foros internacionais. Um discurso fortemente contestado internamente. Em Genebra, por exemplo, a "Rodada do Uruguai" enfrenta o egocentrismo de países democráticos europeus, reféns de uma agricultura ultrapassada. Em Bruxelas, vive-se os ajustes finais para o mercado único dos Doze, observando, com preocupação, a desestruturação das antigas repúblicas soviéticas. Em Tóquio, consolida-se um epicentro de prosperidade da Bacia do Pacífico, enquanto Washington aprende a viver num incômodo mundo sem rival militar.

Longe de uma "ordem mundial" consolidada, o mundo dividido convive com uma multipolaridade. Os Estados Unidos constituem seu principal ator nos campos econômico, comercial e b́lico. A competiçáo e a concertaçáo, presentes nas reunióes do G-7, indicam a opção adotada para enfrentar as turbulências peculiares a um mundo em rápida trans- 
formação. Uma concertação que os países industrializados têm rcalizado com competência nas questôes comerciais e geoestratégicas.

O colapso do comunismo coloca em evidência a oposiçáo entre dois modelos de capitalismo analisados por Michel Albert no seu trabatho "Capitalisme versus Capitalisme" (1991). Um "neo-americano" baseado no sucesso individual e no benefício financeiro de curto prazo. Outro, do Reno, centrado na Alemanha, Suiça e Austria, com muitas semelhanças com o do Japáo. Este capitalismo valoriza o sucesso coletivo, a busca do consenso, o horizonte de longo prazo. Ambos baseiam-se na livre determinaçáo de preços no mercado e na livre propriedade dos meios de produção. No entanto, sáo modelos distintos, que estáo se rivalizando num novo confronto ideológico.

O primeiro, é fonte permanente de heróis empreendedores de grande sucesso. Um sucesso acompanhado pelo aumento dos iletrados e pelo crescimento da pobreza, que alcança $17 \%$ da populaçáo nos Estados Unidos e $12 \%$ na Grä-Bretanha, contra $8 \%$ na Suiça e $5 \%$ na Alemanha Ocidental, antes da sua reunificação. Este modelo está gerando uma alarmante dualidade nos Estados Unidos. Dualidade visível na periferia das grandes cidades e tão ameaçadora quanto aquela conhecida nas megalópoles dos países menos desenvolvidos do hemisfério sul. Que economia de mercado os países intermediários estão buscando consolidar?

O mais indicado é aquele baseado nos princípios do esforço articulado e na cooperaçáo, presente na maioria das empresas globais que se inspiram nos métodos gerenciais adotados no Japão. Métodos que temperam o individualismo triunfante, peculiar das estruturas hierarquizadas de perfil militar. Foram estes valores de competição solidária que permitiram a constituiçáo de cadeias setoriais competitivas, em países derrotados na guerra, como Alemanha e Japão, ou debilitados pelo caos monetário, como Brasil e Colômbia.

\section{Uma agenda para o próximo século}

A Agenda 21 resulta de um amplo esforço coordenado pelo Secretário Geral da Conferência, Maurice Strong. Um esforço de concepção aplaudido. Um documento, no entanto, passivo, enquanto a ele náo forem dados prioridade política e recursos para sua implantação. Prioridade de recursos que dependem da iniciativa de cada país e da comunidade das naçóes que se manifesta anualmente na Assembléia Geral das Naçóes Unidas. 
A Agenda foi concebida partindo de trabalhos das comissóes de especialistas. Estes trabalhos resultaram em documentos técnicos que foram submetidos à apreciação das comissóes preparatórias. Finalmente coube a essas comissōes submeter suas recomendaçōes aos governos. Processo longo que levou mais de dois anos. Processo complexo que foi permeado por conflitos permanentes entre os valores da ciência e a lógica da política. Os valores da ciência, baseados no universalismo e no ciclo longo. A lógica da política movida pela viabilidade da açáo de curto prazo. Coube à diplomacia temperar esses conflitos mantendo-os no limite do possível. Com isso avanços respeitáveis foram obtidos de um lado e de outro, textos estéreis foram produzidos.

A estruturação da agenda baseia-se em quatro grandes temas que enfatizam os grandes desafios da humanidade e a importância da solidariedade e da cooperação internacional. A questáo do desenvolvimento é abordada nos oito primeiros capítulos que tratam das dimensóes econômicas e sociais. Os desafios ambientais merecem quatorze capítulos dedicados à conservaçáo e gestão de recursos naturais. Sete capítulos abordam o papel a ser desempenhado pelos grupos sociais e sua consolidação. Finalmente onze capítulos são dedicados aos meios de implantaçáo sem, no entanto, especificar a fonte dos montantes necessários para a mesma. Nesses últimos capítulos tornam-se evidentes os conflitos sócio-políticos decorrentes do sistema econômico vigente.

Cada um dos quarenta capítulos da Agenda 21 identifica as bases para ação. São objetivos, atividades, instrumentos no campo da ciência e da tecnologia, necessidade de talentos humanos e de competência institucional. Uma descriçáo detalhada que carece, no entanto, de indicadores e de metas quantificáveis. Indicadores e metas que permitiriam avaliar, por exemplo, o êxito alcançado no combate à miséria e na elevação dos padróes de consumo.

A ausência de indicadores e metas na Agenda 21 torna difícil a sua avaliação periódica. As comissóes de especialistas que estiveram na origem dos documentos preparatórios devem agora se debruçar na decodificaçáo dos diplomas internacionais aprovados. A mobilização dos atores engajados na preparaçáo da UNCED é imprescindível na implantaçăo das recomendaçōes. É provável que o sistema onusiano reoriente suas prioridades e açóes com base nas recomendaçóes aprovadas. Um resultado inicial mas insuficiente diante do vulto dos desafios levantados.

Países europeus desenvolvidos assumiram compromissos públicos de destinar parcelas mais elevadas de recursos financeiros à questão ambiental. Foi o caso da Alemanha, Holanda, França e dos países nórdicos. 
O Canadá se comprometeu a reorientar sua ajuda externa e suas agências dedicadas à pesquisa sobre o desenvolvimento. A política interna norte-americana e a ausência do Primeiro Ministro do Japáo tornaram ainda mais difíceis as negociações para criação de novos mecanismos financeiros imprescindíveis à implantaçáo da Agenda acordada. A sensibilidade européia não foi suficiente para influir nas prioridades norte-americanas e japonesas.

Sem novos mecanismos econômicos voluntários, restava a adoçáo em nível internacional, do princípio do "poluidor-pagador". Adotado por vários países desenvolvidos, endossado pela Comunidade Européia dos Doze, a "ecotaxa" permitiria a constituiçăo de um fundo de gestăo comum. A transferência líquida de recursos - de países mais industrializados e mais poluidores a países menos industrializados e menos poluidores - foi uma ameaça suficiente para estancar esta proposta.

O discurso futurista e generoso dos líderes mundiais limitou-se a açóes gerais, sem correspondente contrapartida para a sua viabilizaçáo. A "ecotaxa", considerada pertinente nos limites do território de cada país desenvolvido, foi rejeitada quando proposta em nível mundial. Uma rejeição a ser analisada à luz da "ética planetária" ardorosamente defendida no encontro do Rio de Janeiro.

Em paralelo ao esforço de negociaçáo no âmbito internacional, cada país deverá encontrar soluçóes próprias baseadas nas suas realidades econômicas, políticas e sociais. Para isto um novo entendimento entre a comunidade técnico-científica, os políticos e a diplomacia se torna necessário. A ausência de uma verdadeira comunicaçáo entre os que decidem nos foros nacionais e internacionais e aqueles responsáveis pela implantaçáo das decisóes, constitui um perigoso fosso no qual desaparecem iniciativas meritórias e projetos oportunos.

\section{Nossa responsabilidade comum e imediata}

A difícil implantação da Agenda 21 não exime cada país de assumir sua responsabilidade com iniciativas prioritárias. Iniciativas no âmbito do monitoramento ambiental e da educação ambiental são necessárias para promover alianças setoriais. A sensibilidade geoestratégica e o engajamento da maioria são iniciativas acessíveis às pessoas anônimas, cuja contribuiçáo é determinante para transformar sonhos em realidade, utopias em revoluçóes, princípios em resultados. Elas constituem pontos de partida para a assunçáo de uma responsabilidade comum e imediata. 
O monitoramento ambiental baseia-se em indicadores que permitem medir a degradaçáo ambiental e divulgar dados assimiláveis pela maioria das pessoas. Essa divulgação é capaz de gerar uma nova consciência. Consciência apoiada em indicadores de qualidade do ar, água, solo, que permitem esclarecer onde estamos e aonde queremos chegar. A divulgação através dos meios de comunicação dos níveis de poluição e dos padrōes a serem alcançados para reduzí-la constitui uma condiçăo necessária para a adoçáo do princípio do poluidor-pagador.

A educação ambiental começa na família, continua na escola, no bairro, em volta da moradia, nas propriedades rurais, na cidade e nas empresas - enfim em cada espaço onde um ser humano decidiu se tornar responsável por geraçōes do futuro. Um ser que zela pelos recursos naturais que lhe estáo sendo emprestados e que servirão às geraçóes vindouras. Na escola, a educação ambiental se insere em todas as disciplinas, na universidade deve estar presente em todos os currículos. É um conhecimento a ser adaptado à realidade e vocaçáo de cada município com base em princípios comuns.

A Universidade de São Paulo, por exemplo, se debruçou sobre os doze temas da reuniáo mundial. Uma comissão criada pelo Reitor da USP, Prof. Roberto Lobo, teve a oportunidade de mobilizar os docentes interessados através de um amplo fórum de debates. $O$ documento final do FÓRUM-USP de Meio-Ambiente e Desenvolvimento, editado pelos professores Oswaldo Massambani e Sylvia Suzana Campiglia, sob a coordenação do Prof. Ruy Laurenti, demonstra a viabilidade da Universidade se mobilizar em torno de temas prioritários.

Foi também no espaço universitário que acadêmicos e diplomatas dedicados à questão do meio-ambiente discutiram as medidas necessárias para a preparação da conferência mundial. Uma das propostas surgidas foi a realizaçáo de um curso para jornalistas especializados. Esse curso ministrado com êxito, contou com a participação de vários cientistas, revelando a importância da cooperaçáo dos meios de comunicaçáo com a Universidade em assuntos ambientais.

Vale lembrar também, o exemplo do projeto FLORAM, elaborado por uma equipe interdisciplinar que, ao longo de dois anos, preparou um projeto de reflorestamento e florestamento em que se combinam aspectos ambientais, sociais e econômicos.

Em 1989 teve início a elaboraçáo do projeto FLORAM (veja revista Estudos Apanfados v.4, n.9/1990). O projeto prevê o florestamento de 20 milhóes de hectares no País (2,3\% do território brasileiro). Nele 
estão previstos florestamentos energéticos/industriais, ecológicos, híbridos, corretivos/protetores, de re-enriquecimento de pinheirais, de fitomassa/industriais, de re-adensamento de florestas galerias e um programa especial para os sertóes secos.

O projeto FLORAM oferece uma contribuição para aliviar graves problemas ambientais, sociais e econômicos decorrentes da degradação florestal em várias regióes do País. O projeto se caracteriza como uma proposta brasileira para uma iniciativa mundial. Através do florestamento de $\mathbf{2 0 0}$ milhôes de hectares, pode ser "seqüestrado" o excesso de 115 bilhóes de toneladas de $\mathrm{CO} 2$. Esse "seqüestro" reduziria o risco de transformaçóes climáticas causadas pelo "efeito estufa" .

Alianças setoriais, favorecem o acordo entre parceiros que compartilham mentalidades convergentes. É a procura de amplas associaçōes em torno de determinados projetos ambientais. Cabe às empresas externar seu compromisso em relação ao meio-ambiente. Sua responsabilidade ambiental se estende da aquisiçáo das matérias-primas ao uso final dos seus produtos pelos seus clientes. Os relatórios de impacto e a auditoria ambiental da produçáo ao pós-venda constituem a base de importantes alianças setoriais a serem firmadas. Várias empresas já são atores destacados na concepção e execução de projetos preventivos e corretivos de problemas ambientais.

A sensibilidade geoestratégica é necessária na condução da causa do meio ambiente. Há notáveis modificações no comportamento da opinião pública. Os "subversivos verdes" de 1972, hoje são refúgios de idéias para uma sociedade ansiosa em encontrar soluçóes para os problemas ambientais. A América Latina libertou-se de ditaduras para aplaudidos regimes democráticos que ainda toleram políticas de rendas perversas que aprofundam a dualidade. No contexto mundial cresce a distância entre o discurso da solidariedade e a prática do egocentrismo. A compreensáo desta evoluçáo das mentalidades é necessária para encontrar novas formas de reconciliar a ecologia com a economia.

O imprescindível engajamento da maioria será alcançado com a decodificação das convençôes e acordos internacionais, em metas inteligíveis. Os discursos críticos e as mensagens genéricas diluem-se no complexo mosaico de problemas econômicos e sociais enfrentados pela sociedade. As organizaçóes não-governamentais são rclevantes pois são elas uma importante fonte de energia propulsora de novas mentalidades. No entanto, se não houver a decodificação de suas teses para o conjunto da população, o engajamento da maioria será tênue. A UNCED-92 será, então, mais um capítulo de liçóes aprendidas sobre as dificuldades do entendimento global. 
Monitoramento ambiental, educaçáo ambiental, alianças setoriais, sensibilidade geoestratégica e engajamento da maioria constituem iniciativas para uma estratégia de meio-ambiente em prol de um planeta ameaçado. $O$ compromisso de erradicação da miséria e a adoção dessas iniciativas, são formas de compartilhar a nossa responsabilidade comum, no país que melhor retrata as contradições e disparidades do mundo contemporâneo.

A tradução dos princípios em estratégias e estas em resultados, constitui agora o principal desafio. Ao "espírito do Rio", deve-se dar concretude através da implantaçáo e da avaliaçáo de políticas públicas. Esse é o compromisso a ser assumido por aqueles que tanto se engajaram na preparação da reunião mundial, cujas recomendaçóes devem ser agora colocadas em prática. Um compromisso prioritário para a Universidade e a comunidade científica.

A Agenda 21 é um ponto de partida auspicioso, mas desprovido de indicadores e de meios de implementação. A liberalização do comércio internacional e os programas emergenciais de erradicaçáo da miséria enfrentam o egocentrismo de segmentos organizados da sociedade. Os maiores produtores e consumidores de petróleo se opuseram à adoçáo do princípio do poluidor-pagador. A manifestaçáo dos agricultores europeus contra a liberalização do comércio internacional e a resistência dos países industrializados em expandir a cooperação internacional são exemplos de forças inibidoras. Forças que dificultam a traduçáo dos princípios acordados na Rio-92 em estratégias viáveis e resultados tangíveis para mudanças de rumos.

Jacques Marcovitch é diretor do Instituto de Estudos Avançados da USP e professor da Faculdade de Economia e Administração da USP.

Este texto foi escrito com base no pronunciamento feito pelo autor na sessáo plenária sobre a Agenda 21 do workshop "Ecos da Eco 92", rcalizado pela SBPC com o apoio do IEA nos dias 13, 14 e 15 de julho de 1992, em São Paulo. 